\section{ARA GÜLER ILE BIRLIKTE}

\section{Simber Atay ${ }^{*}$}

Meltem

İzmir Akdeniz Akademisi Derģisi

No. 7, Yaz 2020, 6-30, DOI 10.32325/iaad.2020.4

* Dokuz Eylül Üniversitesi, Güzel Sanatlar Fakültesi, Fotoğraf Bölümü Öğretim Üyesi.
Buz gibi bir rüzgâr esiyordu... Kentin öbür ucundan, kampüsten geliyorduk. Galeri'ye vardığımızda, hepimiz soğuktan donmuştuk. Sonra içeriye girdik. Algılarımın çözülmesi, biraz zaman aldı. Kokteyl henüz başlamıştı. Çok kalabalıktı ama gürültü yoktu. $\mathrm{O}$ şık davetliler sanki telepatiyle anlaşıyorlardı. Garsonlar zarif manevralarla, insanların arasından geçerek sürekli servis yapıyordu. Hercai menekşe yaprağıyla süslü, somonlu tartoletlerden yedim. Beyaz şarabın serin buğusu, kırmızı şarabın yağmurda bağ rayihası... Aydınlatma ne kadar yumuşaktı... Dışarısı Alfred Sisley kışıydı, orası kesin ama içerisi, karar vermek zordu, galiba bu bir Art Nouveau ılıklığıydı. Derken herkes açılıș konuşmasını dinlemeye çağrıldı. L'homme qui aime Smyrne/İzmir'i Seven Adam nam-ı diğer Lucien Arkas sergiyi açtı! Arkas, tek tek bütün misafirlerin hatırını sorarak nazik sohbetlerini sürdürürken, davetliler de yavaş yavaş sergiyi gezmeye koyuldular, büyük bir beğeniyle. Tabii, sonraki günlerde yeniden gelecekler, diğer birçok ziyaretçiyle birlikte, galerinin büyülü atmosferini teneffüs etmek ve bu eşsiz Einfühlung olanağını değerlendirmek üzere.

Ara Güler, 1999 yılında Dokuz Eylül Üniversitesi, Güzel Sanatlar Fakültesi, Fotoğraf Bölümü’ne ziyarete gelmişti. Ünlü İzmirli fotoğrafçı, Yusuf Tuvi, kendisine eşlik ediyordu. Meslektaşlarım ve öğrencilerimiz, kocaman bir masanın etrafında toplanmış, hayranlıkla kendisini dinliyorduk. Bazllarımız, bu müstesna anları belgeliyordu. Konuşurken uzandı, usulca, hemen yakınındaki bir öğrencinin makinasını eline aldı ve o öğrencinin bir portresini çekti. $\mathrm{O}$ günün ardından film yıkanmıș ve o portre, 9x13 karta basılmıştı. Mat, siyah-beyaz! Fotoğrafa baktım, gençliği, güzelliği, soru soran bakışları ve tebessümünü gördüm. Hayran kaldım, hem resme, hem de Ara Güler'e! Usta'nın mucizevi "Karar Anı" performansına bir kez daha tanık olmuştuk, üstelik birlikteyken; $\mathrm{O}$, bir anlam üreticisiydi, fotoğrafın anlamını 


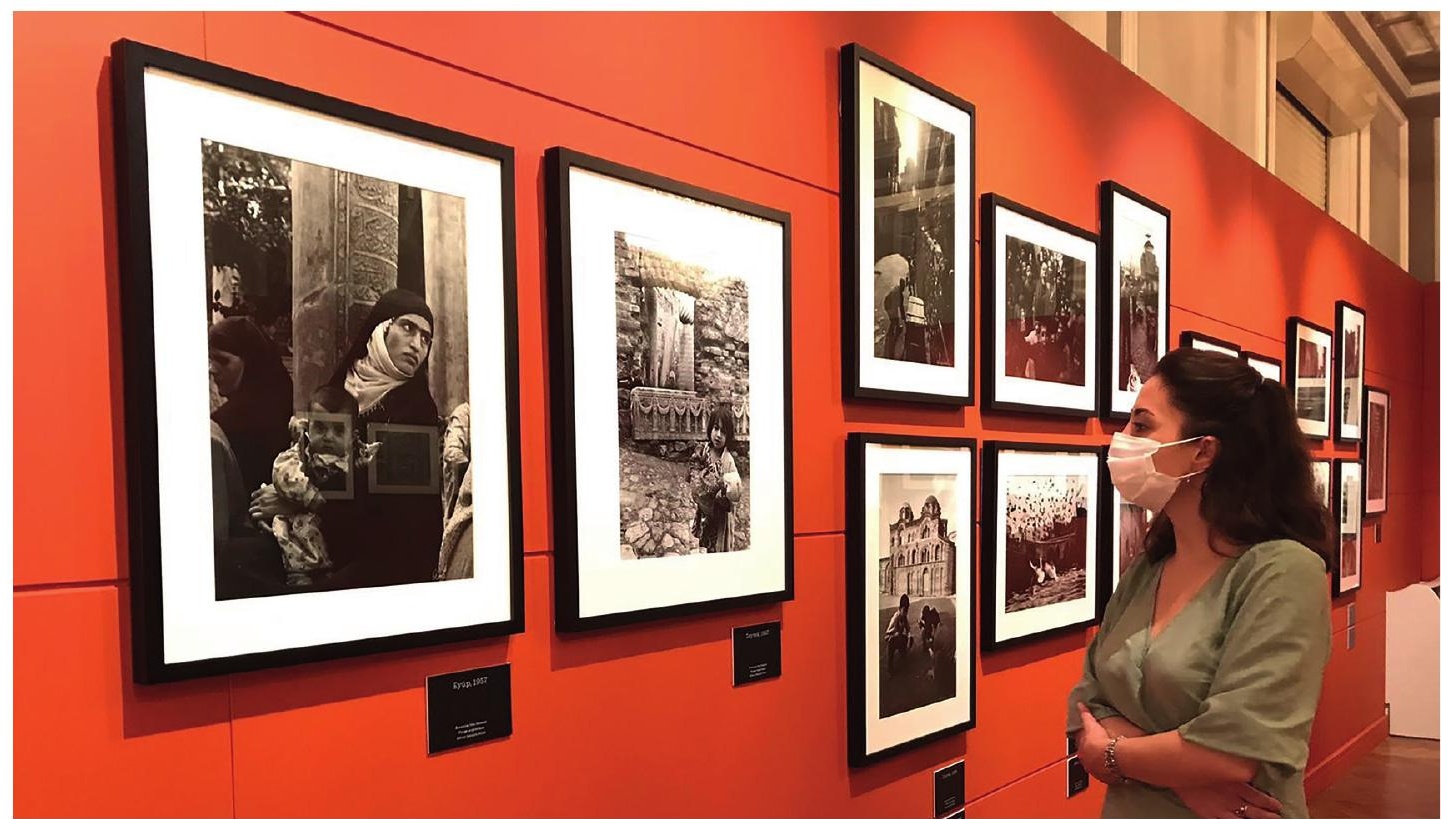

üretiyordu. Birden anladım; ama bunu, bu anlamı kelimelere dökmem imkânsızdı çünkü sezgisel olarak kavramıştım ve bütün bunlar sanırım transandantal bir deneyimdi.

Bir defasında da Ara Güler'in, Beyoğlu'nda sergisine gitmiştik, 2000’lerin başıydı. Galeri'de hoş bir sürpriz oldu, kendisiyle karşılaştık. Büyük bir nezaket göstererek, sergisini bize gezdirdi. Ardından Galatasaray’daki evine davet etti. Dar merdivenlerle çıkılan, kat kat bir bina! Ev, ofis, stüdyo, karanlık odalar... Sahanlıklarda, ünlü fotoğraflarının, paketlenmeye hazır, çoğunluk dijital röprodüksiyonları.. Basamakları tırmanırken, aklıma Reşat Ekrem Koçu'nun İstanbul Ansiklopedisi'nde, 'Abdullah Biraderler' maddesinde buna benzer bir fotoğrafhaneyi tanımlayan satırlarını hatırladım: "Abdullah Biraderlerin İstanbul'daki fotoğrafhaneleri, Beyoğlu'nda... Methali karanlk, merdivenleri çımak ile tükenmez binanin en üst katında idi...". Belirtmeliyim bu bir alıntı prosedürü değil, bir bellek kaydı (!). Abdullah Biraderler, İmparatorluğun en seçkin fotoğrafçllarındandı; Ara Güler, Cumhuriyet'in en seç-

1 Reşad Ekrem Koçu, İstanbul Ansiklopedisi, cilt 1 (İstanbul, 1947), 36. kin fotoğrafçısıydı. Fotoğraf tarihi, bir açıdan Memetik Tarihi idi, en azından İstiklâl Caddesi'nde...

Aydın'daydık. Aydın Belediyesi'nin düzenlediği, 2. Ulusal Fotoğraf Yarışması'nın jürisindeydik. Bir yandan jüri üyeleri, jürinin çalışma yöntemini tespit ederken diğer yandan Belediye, cömert ikramlarıyla masaları donatıyordu... İncir ve üzüm, ambrosia ve nektar, Ege'nin müstesna misafirperverliği... Derken bir baktım, Ara Güler ve Sabit Kalfagil, fotoğrafların başına geçmiş, çalışmaya başlamışlard. Zihinleri ne kadar berraktı! Seçimleri ne kadar isabetliydi! Ne kavramsalcı sofizm; ne de postmodern rölativizm, semtlerine bile uğramamıştı! Saf fotoğraf bilinci! Günün sonunda şunu anlamıştım: Onlar yalnızca birer fotoğraf ustası değildi; aynı zamanda ideal fotoğrafın gerçek birer temsilcisiydiler.

\section{I Fotoğrafçı, yaşamın mitolojik tanı̆̆ıdır. / /}

Fotoistanbul 2. Beşiktaş Uluslararası Fotoğraf Festivali'nde, “Ara'yı Anlamak" paneli düzenlenmişti. Etkinlik, Pera Müzesi'ndeydi. Salon 


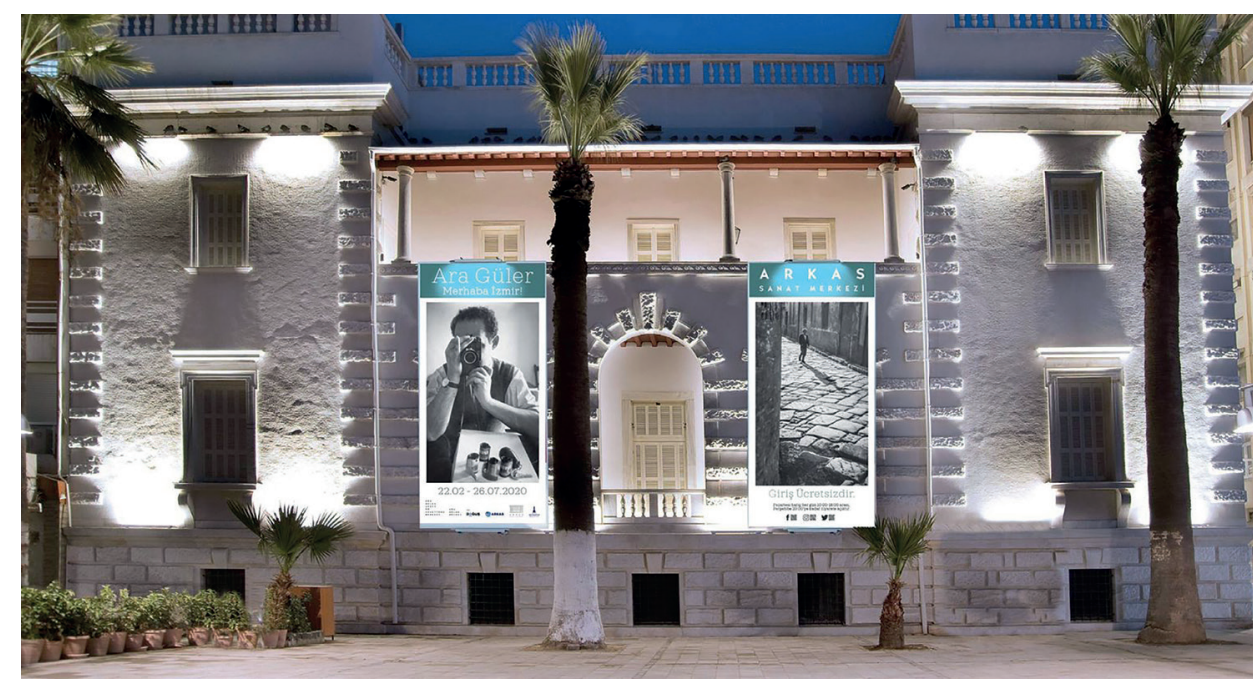

dolmuş taşmıştı. Coşkulu ve meraklı bir kalabalık vardı ve fotoğraf camiamızın hemen bütün yıldızları oradaydı. En son, Usta, teşrif etti ve panel başladı. Panelistlerden biri, Coşkun Aral, diğeri Paul McMillen, üçüncüsü de bendim. Konuşmaların kaydı, internette mevcuttur. Ama birkaç saptamamı, mealen aktarmak isterim. Ara Güler'in poetikası, XX. yüzyıl fotoğrafının iki temel paradigmasına birden sahiptir:

1- Henri Cartier Bresson'un Perfeksiyonizmi: Cartier-Bresson'un perfeksiyonizmi, "Karar Anı" prensibine dayalıdır. Buna göre, Cartier-Bresson'un ifadesiyle: "Fotoğraf, saniyenin bir kesitinde, bir olayın önemini ve o olaya doğru ifadesini veren biçimlerin tam bir organizasyonunu, eşzamanlı olarak tantmaktır." Dolayısıyla "Karar Anı”, mükemmel enstantane, mükemmel saptama, mükemmel kompozisyon, mükemmel kalite ve net anlam demektir. Fotoğrafçı, yaşamın mitolojik tanığıdır. Yanı sıra, söz konusu prensip, Zen kaynaklıdır. Bu bağlamda, fotoğrafçı, fotoğraf enstrümanına dönüşmüştür ve mükemmellik doğaldır.

2- Robert Frank'in Non-perfeksiyonizmi: Toplumcu-gerçekçi eleştiri, varoluşçu yabancılaşma, disütopik travmalar, zaman zaman yeni realist vizyon araştırmalarına neden olmuştur. Robert Frank'in, alternatif non-perfeksiyonizmi de böyle bir girişimdir; ancak bu girişim, fotoğrafik dilyetisinin evrim sürecinde bir devrim yaratmıştır ve ardından bu iki anlayış -perfeksiyonizm ve non-perfeksiyonizm- paralel gelişimlerine devam etmiştir. Robert Frank'in stili, öz-düşünümseldir, eleştireldir, aşkın bir muhalefet performansını yansıtır ve şiirseldir. Cartier-Bresson perfeksiyonizmindeki teknik virtüozite, Robert Frank'in non-perfeksiyonizminde terkedilmiştir. Diğer bir ifadeyle; bulanık unsurlar, öznel kamera açıları, hareket izlenimleri, kimi zaman iri grenler ve böylece yorumlanan kayıtsız çehreler, birçok toplumsal sorunun uç verdiği yalnızlık ve iletişimsizlik ortamları...

Ara Güler, genellikle perfeksiyonisttir; ama bazen de kimi ortamlar ve insanlar dolayısıyla melankoliyi tanımladığında non-perfeksiyonisttir.

Örneğin, Salvador Dali'yi çekerken perfectionist, Aliye Berger'i çekerken non-perfeksiyonist!

Haliç’te perfektionist, Beyoğlu sazlarında non-perfeksiyonist!

Galata Köprüsü’nde bazen perfektionist, bazen non-perfeksiyonist!

Bir de, "Ah! Kayı İstanbul" teranesi var. Bu konu, derin, kültürel ve politik bir konudur. Ama zaman akar, değişiklik kaçınılmazdır, trajik olan dönüşüm değil, yok oluştur ve nos- 
talji bizi hasta eder. Ama Ara Güler, o Kayıp İstanbul'u kaybolmadan yakalamış, belgeselci ve fotojurnalist kimliği ve refleksiyle kentin bellek kayıtlarını oluşturmuştur. O zaman, Ara Güler’in İstanbul fotoğraflarına bakarak kenti görebiliriz, bütün kuşaklar görebilir. Böylece yok oluş, en azından tanımlanabilir hale gelir! Kaynakça

Koçu, Reşad Ekrem. İstanbul Ansiklopedisi. 1:36. İstanbul, 1947.

Cărtărescu, Mircea. Orbitor-Göz Kamaştırıcı. Cilt 1. Çeviren Sunia İliaz Acmambet. İstanbul: Ayrıntı Yayınları, 2014.

Mircea Cartarescu'nun, Orbitor romanında altını çizdiği gibi: "Hafıza zamanı olmayan krallığın zamanı"dır. ${ }^{2}$

Yanı sıra, Ara Güler, fotoğraf tarihinde ve çağdaş kültür ortamında klasik ve hümanist bir figürdür. Çünkü:

1- Fotoğraflarını çektiği insanlar, -kim olursa olsun!- insanlık ailesini temsil eden birer kahramana dönüşmüştür.

2- Fotoğraflarl; model, kriter ve kültürel kod olarak, fotoğraf tarihi, fotoğraf kuramları ve fotoğraf estetiği bağlamında yaratıcı stratejileri tartışabileceğimiz birer ideal yapıttır. 3- Arkeolojik alanlar, yapılar ve eserlerle çok ilgilidir. Afrodisyas, O’nun klasik kültüre karşı duyarlılığının anıtsal göstergesidir.

Beyoğlu'nda, Ara Kafe'deydik. Öylesine takıllyorduk. Baktık ki Usta, mekâna uğramış. Gelmiş, kapıya yakın bir masada oturuyor. Ortam loştu ama onun oturduğu yer aydınlıktı. Kapıdan süzülen ışık mı, yoksa Usta'nın aurası mı? Ayırt etmek güçtü. $O$, herkesi selâmlıyor ve herkes de O'na sayglarını ve sevgilerini sunuyordu. Nefesimi tutarak, seyrediyordum. Sonra bir gün Usta'yı kaybettik. Ama bir de baktım, İzmir'de, Arkas Sanat Merkezi'nde yine karşıllaşmışız. Sergiler böyledir, aynı şekilde yer aldıkları galeriler ve müzeler de... Fantastik randevu mekânlarıdır.

Merhaba Usta!

İzmir-Nisan 2020

\footnotetext{
* "Ara Güler, Merhaba İzmir!" Sergisi, Arkas Sanat Merkezi'nde, 22.02-26.07.2020 tarihleri arasında serģilenmiştir.
}

2 Mircea Cărtărescu, Orbitor-Göz Kamaştırııı, cilt 1, çev. Sunia Illiaz Acmambet (İstanbul: Ayrıntı Yayınları, 2014), 82. 